\title{
Formation of the high-energy ion population in the earth's magnetotail: spacecraft observations and theoretical models
}

\author{
A. V. Artemyev, I. Y. Vasko, V. N. Lutsenko, and A. A. Petrukovich \\ Space Research Institute, RAS, Moscow, Russia \\ Correspondence to: A. V. Artemyev (ante0226@gmail.com)
}

Received: 12 May 2014 - Revised: 8 September 2014 - Accepted: 10 September 2014 - Published: 13 October 2014

\begin{abstract}
We investigate the formation of the high-energy $(E \in[20,600] \mathrm{keV})$ ion population in the earth's magnetotail. We collect statistics of 4 years of Interball / Tail observations (1995-1998) in the vicinity of the neutral plane in the magnetotail region $\left(X<-17 R_{\mathrm{E}},|Y| \leq 20 R_{\mathrm{E}}\right.$ in geocentric solar magnetospheric (GSM) system). We study the dependence of high-energy ion spectra on the thermal-plasma parameters (the temperature $T_{i}$ and the amplitude of bulk velocity $v_{i}$ ) and on the magnetic-field component $B_{z}$. The ion population in the energy range $E \in[20,600] \mathrm{keV}$ can be separated in the thermal core and the power-law tail with the slope (index) $\sim-4.5$. Fluxes of the high-energy ion population increase with the growth of $B_{z}, v_{i}$ and especially $T_{i}$, but spectrum index seems to be independent on these parameters. We have suggested that the high-energy ion population is generated by small scale transient processes, rather than by the global reconfiguration of the magnetotail. We have proposed the relatively simple and general model of ion acceleration by transient bursts of the electric field. This model describes the power-law energy spectra and predicts typical energies of accelerated ions.
\end{abstract}

Keywords. Magnetospheric physics (magnetospheric configuration and dynamics; magnetotail; plasma sheet)

\section{Introduction}

The investigation of the high-energy $(E \in[30,500] \mathrm{keV})$ ion population in the earth's magnetotail has a long history and is motivated by two primary reasons. Ions accelerated in the magnetotail up to several tens of keVs can serve as a source for the ring-current ion population responsible for significant deformations of the inner-magnetosphere magnetic field (e.g., Daglis et al., 1999). On the other hand, observations of high-energy ions in the magnetotail can be considered as the indication of the magnetic reconnection in the current sheet (e.g., Birn et al., 2012).

Starting from very first observations by IMP-7 spacecraft, the energy spectrum of high-energy ions was recognized as the power-law spectrum with a phase-space density of $f \sim E^{-\gamma}$ and an index of $\gamma \sim 4-6$ for $E \in[100,500] \mathrm{keV}$ (Fan et al., 1975; Sarris et al., 1976). The typical value of the upper ion energy was established by Baker et al. (1979) - the substorm activity in the magnetotail can result in the generation of $\sim 300 \mathrm{keV}$ ions. Moreover, it was mentioned that the ion acceleration up to $300 \mathrm{keV}$ is accompanied with injections in the inner magnetosphere. Further observations of high-energy $(E>100 \mathrm{keV}$ ) ions by IMP-7 (eight at $X \sim-30-40 R_{\mathrm{E}}$ ) confirmed that the distribution of the phase space density is $f \sim E^{-\gamma}$ and showed that there is the separation between two populations of accelerated ions at the energy $E^{*} \sim T_{i}(\gamma+1)$, where $T_{i}$ is a thermal-ion temperature (Sarris et al., 1981). The energy spectrum of ions with $E<E^{*}$ resembles the Maxwellian spectrum (or soft power law) and can be considered as a natural prolongation of the thermal population into the high-energy range. The population with $E>E^{*}$ exhibits the clear power-law energy distribution. This population possibly relates to some mechanism of effective acceleration in the magnetotail. Observations of bursts of high-energy ions with $f \sim E^{-5}$ accompanied by simultaneous rapid variations of the $B_{z}$ magnetic-field component (in the geocentric solar magnetospheric (GSM) system) indicated that the magnetic reconnection is likely responsible for local ion acceleration up to high energies in the magnetotail (Kirsch et al., 1981). Observations of a localized maximum of energetic ion fluxes in the current sheet of the magnetotail support this conclusion (Pavlos et al., 1985). However, the spatial distribution of high energy ion fluxes in 
the magnetotail suggested that the general plasma convection also plays an important role in ion acceleration. For example, statistics collected by IMP-8 spacecraft clearly showed that the maximum of fluxes is observed at the dusk flank of the magnetosphere (Meng et al., 1981), where ions drift due to the quasi-stationary gradient drift.

The detailed investigation of the relationship between fluxes of high-energy ions and thermal-plasma characteristics became possible with the launch of ISEE-1,2,3 and AMPTE-IRM/CCE spacecraft. Using ISEE-3 measurements in the deep magnetotail ( $X$ down to $-220 R_{\mathrm{E}}$ ), Scholer et al. (1983) showed that fluxes of energetic $(E>30 \mathrm{keV})$ ions are predominantly coming from the near-earth region. Thus, there is no effective local mechanism of ion acceleration at such distances. ISEE-1 measurements of high-energy ions $(E \in[30,500] \mathrm{keV})$ in the near-earth magnetotail $X>$ $-20 R_{\mathrm{E}}$ confirmed previous suggestions which stated that the ion spectrum can be separated into the tail of the thermal population $(E<100 \mathrm{keV})$ and superthermal particles with the power-law energy distribution $(E>100 \mathrm{keV})$ (Moebius et al., 1983; Ipavich and Scholer, 1983; Scholer et al., 1985). The primary origin of the second population is the magnetic reconnection in the magnetotail current sheet. Statistics of AMPTE-IRM showed that fluxes of high-energy protons strongly depend on geomagnetic activity, while the slopes of the energy spectrum are almost the same for different activity levels (Baumjohann et al., 1990b). Later, the same results were obtained by broader Cluster statistics (Haaland et al., 2010). Simultaneous observations of fluxes of high-energy ions at AMPTE-IRM and AMPTE-CCE demonstrated two interesting features. Ion fluxes are initially observed in the tail region $X \sim-20 R_{\mathrm{E}}$ by AMPTE-IRM and, only after certain time, AMPTE-CCE recorded the flux increase in the near-earth region $X \sim-8 R_{\mathrm{E}}$ (Kistler et al., 1990). Moreover, the ratio of fluxes of energetic $\mathrm{H}^{+}$and $\mathrm{O}^{+}$ions is almost constant along the magnetotail (Kistler et al., 1990). Thus, we deal with some mechanism of the ion acceleration in the tail $X \sim-20 R_{\mathrm{E}}$. There is no ion acceleration in the nearearth region, but rather transport of accelerated ions toward the earth. The series of publications (Christon et al., 1988, $1989,1991)$ were devoted to the fine structure of ion spectra in the wide energy range $E \in[50 \mathrm{ev}, 1 \mathrm{MeV}]$. Combined measurements of two experiments (thermal and superthermal ion measurements) onboard ISEE-1 spacecraft allowed us to confirm that the ion energy distribution should be approximated by the kappa power-law function with $\gamma \sim-5$ in quiet magnetotail conditions. In contrast, for disturbed conditions the increase of fluxes of high-energy ions does not allow to use the single energy distribution for low and high energies, i.e., the high-energy ions form the independent population (Christon et al., 1991).

Many years of measurements of Geotail and Cluster spacecraft in the earth's magnetotail helped to understand the correlation between fluxes of high-energy ions and solarwind conditions (Ohtani et al., 2011; Cao et al., 2013). The analysis of high-energy ion spectra collected in the magnetotail by Cluster and Geotail during different geomagnetic conditions showed that the ion acceleration is likely local and should correspond to some transient processes (e.g., magnetic reconnection or bursts of electric fields) in the current sheet (Sarafopoulos, 2008; Haaland et al., 2010; Luo et al., 2014). Although both Cluster and Geotail can provide extremely broad statistics, the energy resolution of measurements of high-energy ions is relatively low in both experiments: Geotail/EPIC (Williams et al., 1994) and Cluster/RAPID (Wilken et al., 2001). This restriction does not allow us to distinguish many fine structures of ion-energy spectra like the energy knee (Sarafopoulos et al., 2001) or beams of almost monoenergetic ions (Lutsenko and Kudela, 1999). The better energy resolution available at the Interballtail/DOK-2 experiment (Lutsenko et al., 1998) can help to resolve the dependencies of ion energy spectra on thermalplasma (or magnetic-field) parameters. Investigation of such dependencies should provide the necessary information to determine roles of different mechanisms of ion acceleration in the magnetotail.

There are several mechanisms which can be responsible for the ion acceleration in the earth's magnetotail. These mechanisms can be separated into two groups: quasistationary mechanism and transient mechanism. The first group of mechanisms includes the quasi-stationary dawndusk electric field $E_{y}$ as the main ingredient (Coroniti and Kennel, 1973). Ions can gain energy moving along open orbits (the so-called Speiser trajectories, see Speiser, 1965, 1967). In this case, the total amount of gained energy is limited by $\sim 2 m c^{2}\left(E_{y} / B_{z}\right)^{2}$ (Lyons and Speiser, 1982; AshourAbdalla et al., 1993). For specific regions in the magnetotail, such acceleration can be effective for a large number of particles. In this case, accelerated particles form so-called beamlets: beams of almost monoenergetic particles observed in the magnetosphere boundary layer (e.g., Bosqued et al., 1993; Ashour-Abdalla et al., 2006; Zelenyi et al., 2007; Grigorenko et al., 2009). For the magnetotail configuration far from the $X$ line, particles can gain $10-20 \mathrm{keV}$ due to this mechanism. However, in the vicinity of the distant $X$ line (at $X<-100 R_{\mathrm{E}}$ ), the acceleration can be more effective due to larger amplitudes of $E_{y}$ (Grigorenko et al., 2011). The acceleration of ions moving along closed orbits can be provided by the slow drift induced by the gradient of the magnetic field, $\partial B_{z} / \partial x$. This drift shifts ions along the dawn-dusk direction, resulting in the ion acceleration by $E_{y}$. This mechanism is more relevant for magnetized electrons (Lyons, 1984; Zelenyi et al., 1990b; Artemyev et al., 2012b). However, ions can also be accelerated (see review Zelenyi et al., 2013, references therein). Efficiency of such an acceleration process can be increased by quasi-stationary magnetic-field fluctuations (Greco et al., 2000).

The upper limit of the ion acceleration in a quasistationary electric field is defined by the potential drop across the magnetotail $\sim 20-50 \mathrm{keV}$ (Angelopoulos et al., 1993; 
Wang et al., 2009). Thus, to describe the formation of energetic ions with $E>50 \mathrm{keV}$, one should take a look at nonstationary mechanisms. In this case, we deal with short-time bursts of the electric field $E_{y}>50 \mathrm{kV} / \Delta \ell$ with a short-scale $\Delta \ell$ of the localization. One of the most natural sources of such bursts is the transient magnetic reconnection in the magnetotail current sheet (e.g., Wygant et al., 2005). There are two main components of this field: the electrostatic field and induction field. The electrostatic field is produced by the decoupling of ion and electron motions in the vicinity of the reconnection region (e.g., Korovinskiy et al., 2011) and can be responsible for charged-particle demagnetization (Hoshino, 2005; Artemyev et al., 2013, and references therein). In contrast, the induction electric field originates from the rapid evolution of the magnetic-field topology during the magnetic reconnection. This field can be responsible for the effective ion acceleration (Galeev, 1979; Zelenyi et al., 1990a). The general conception assumes that the magnetic reconnection results in ion demagnetization in the vicinity of the $X$ line and local acceleration by the induction electric field. The transient reconnection is a highly localized process both spatially and temporally. Thus, only a relatively small amount of particles can be accelerated in the vicinity of the reconnection site. Accelerated ions are observed in the close vicinity of the reconnection site as bursts of almost monoenergetic particles with energies of $\sim 50-200 \mathrm{keV}$ (Lutsenko, 2001; Lutsenko et al., 2008). In the case of multiple reconnections, these burst from the power-low tail of the ion spectrum (Taktakishvili et al., 1998).

Recent spacecraft observations (e.g., Angelopoulos et al., 2013; Fu et al., 2013a) and numerical models (e.g., Sitnov et al., 2009, 2013) suggest that the significant part of the released magnetic energy is evacuated from the reconnection region by fast plasma flows. The leading edge of such flows is characterized by the specific magnetic-field configuration: the so-called dipolarization front. This front is recognized as the sharp increase of the $B_{z}$ component of the magnetic field with the same increase of the electric field $E_{y}$ (e.g., Runov et al., 2011, and references therein). Particles can be effectively accelerated by dipolarization fronts (Ashour-Abdalla et al., 2011; Birn et al., 2012; Fu et al., 2013b). Simple reflection of ions from the moving front results in the acceleration up to $\sim 10 \mathrm{keV}$ (Zhou et al., 2010), while the resonant ion acceleration can be responsible for the generation of $\sim 100 \mathrm{keV}$ particles (Artemyev et al., 2012a; Ukhorskiy et al., 2013).

Here, we should also mention one additional effective mechanism of ion acceleration/heating in the magnetotail. This mechanism corresponds to the ion interaction with various small-scale fluctuations of the electromagnetic field forming the electromagnetic turbulence (Zimbardo et al., 2010; Zelenyi et al., 2014). The primary source of this turbulence is the interaction of different plasma instabilities which can develop and saturate in the magnetotail (Zelenyi and Milovanov, 2004). According to the numerical modeling, ion interaction with such a turbulent field should result in the particle acceleration in the vicinity of the neutral plane (Zelenyi et al., 2008; Perri et al., 2009; Greco et al., 2010). The natural limitation of possible energy gain corresponds to the particles escaping from the turbulent current sheet due to the fast motion along the curved magneticfield lines (Artemyev et al., 2009b; Perri et al., 2011). In this case, some specific properties of electromagnetic turbulence (like a spatial intermittency) can increase the efficiency of the acceleration (Zelenyi et al., 2011). There are two most natural magnetic-field configurations, including electromagnetic turbulence, where ions can be accelerated up to high energies: the magnetic reconnection region (Onofri et al., 2006) and dipolarization fronts (Ono et al., 2009). Moreover, ions can be accelerated due to the combination of turbulent and regular mechanisms (Grigorenko et al., 2011; Artemyev et al., 2011; Dolgonosov et al., 2013). The interaction of ions with the electromagnetic turbulence can be described as the quasi-linear diffusion of ions in the energy/pitch-angle space (Dusenbery and Lyons, 1989). In this case, the formation of power-law energy distributions of accelerated ions is predicted by the general theory (Hasegawa et al., 1985; Milovanov and Zelenyi, 2001).

In this paper, we investigate spectra of high-energy ( $E \in$ $[20,600] \mathrm{keV})$ ions in the magnetotail. We study the dependence of ion spectra on thermal-plasma parameters and on magnetic-field amplitudes. Owing to high-energy resolution, we can monitor evolution of ion spectra in dependence of the system parameters. We particularly investigate the dependence of the energy value of the spectrum knee on the plasma temperature. We also propose the relatively general model of the ion acceleration in the magnetotail current sheet. This model includes burst of the electric field as the main driver of acceleration and can reproduce the power-law energy distribution of ions.

\section{Data set description}

We use statistics of observations of Interball-tail spacecraft in the magnetotail during the 1996-1998 seasons. We restrict our analysis to the domain $|Y|<20 R_{\mathrm{E}}, X<-17 R_{\mathrm{E}},|Z|<$ $5 R_{\mathrm{E}}$ (hereinafter, the GSM coordinate system is used). The additional criterion is $\sqrt{B_{x}^{2}+B_{y}^{2}}<15 \mathrm{nT}$. Thus, we mostly investigate the close vicinity of the neutral plane of the magnetotail current sheet (Fig. 1 shows fragments of spacecraft orbits). The magnetic field is measured by the ASPI/MIFM experiment (Klimov et al., 1997), thermal-ion moments are gathered by the CORALL experiment (Yermolaev et al., 1997), electron density is gathered by the ELECTRON experiment (Sauvaud et al., 1997), and high-energy ion spectra (without resolved ion species) are collected with record energy resolution $\sim 7-8 \mathrm{keV}$ by the DOK-2 experiment (Lutsenko et al., 1998). To avoid observations in the cold plasma sheet, we use the criterion for electron density, $n_{e}<1 \mathrm{~cm}^{-3}$. ASPI/MIF-M measures three components of the magnetic 


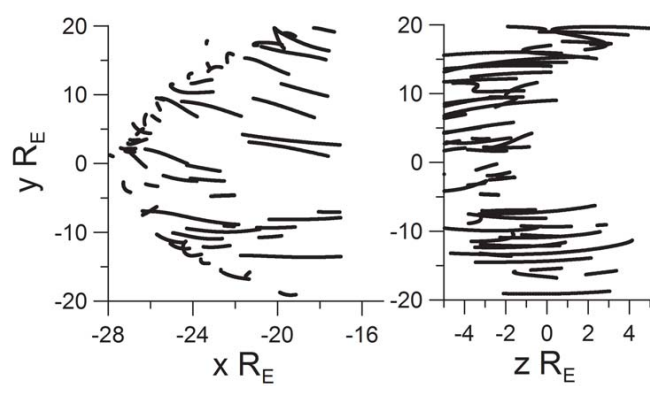

Figure 1. Fragments of Interball-tail orbits used in this study.

field with a time resolution of $\sim 2 \mathrm{~s}$. CORALL provides ion temperature $T_{i}$ and three components of ion bulk velocity $V$ with a time resolution of $\sim 2 \mathrm{~min}$. Time resolution of energetic ion spectra collected by DOK-2 depends on ion fluxes and varies from $\sim 0.1 \mathrm{~s}$ up to $\sim 1 \mathrm{~min}$. To operate with all these data as with the single database, we separate all time intervals of observations into 3 min subintervals. We use such long time subintervals due to low time resolution of the CORALL experiment. For each subinterval, we determine average values of magnetic-field components and average high-energy ion spectrum. Our database includes $\sim 4300$ subintervals when all plasma data and magnetic fields were available.

\section{Ion-energy spectra}

In this section, we discuss high-energy ion spectra observed by Interball-tail. We use the ion temperature $T_{i}$, the amplitude of ion bulk velocity $v_{i}=\sqrt{V_{x}^{2}+V_{y}^{2}}$ (if measurements of $V_{y}$ are unavailable, we use $v_{i}=\left|V_{x}\right|$ ), and the value of the magnetic-field component $B_{z}$ to separate all observed spectra into several subgroups (see Fig. 2). Velocity components $V_{x}$, $V_{y}$ characterize fast plasma flows in the magnetotail and their amplitudes are assumed to be related to the geomagnetic activity (Baumjohann et al., 1990a; Angelopoulos et al., 1992; Cao et al., 2006). It should be noted that all used criteria for $B_{z}, v_{i}$, and $T_{i}$ are applied for $3 \mathrm{~min}$ averaged data. The increase of $T_{i}$ corresponds to the well-distinguished growth of the flux amplitude. This effect can be explained by the expansion of the thermal core of the ion distribution to the highenergy range. The general shape of spectra is more or less the same for all $T_{i}$ ranges. The only exception is cold ions with $T_{i}<1 \mathrm{keV}$. For this temperature range, we observe relatively weak fluxes of high-energy ions up to $E \sim 200 \mathrm{keV}$ and a very pronounced tail of the spectrum $(E>200 \mathrm{keV})$. The presence of this tail can be due to relatively small statistics of events with low temperature. However, it is also possible that such super-energetic ion population is always present, but, for larger ion temperatures, the high-energy fluxes are so high that this super-energetic ion population becomes covered by the main spectrum. We observe a similar spectrum shape (but less pronounced) for $T_{i} \in[1,5] \mathrm{keV}$.

Shape of spectra and flux amplitudes are almost independent of averaged $B_{z}$ values for $B_{z}<10 \mathrm{nT}$ (see Fig. 2b). Only for the extreme conditions with $B_{z}>10 \mathrm{nT}$ do we observe the distinct increase of fluxes for $E>200 \mathrm{keV}$. However, this effect can be due to small statistics of observations of such high $B_{z}$ values. It should be mentioned that the averaging procedure can substantially smooth peaks of $B_{z}$ values associated with small scale structures like dipolarization fronts (a time scale of such peaks is about 10-30 s, see Runov et al., 2011). Thus, we consider here the correlation between highenergy ion spectra and magnetic-field amplitudes characterizing large-scale structures.

High-energy ion fluxes and spectrum shapes do not vary substantially with $v_{i}$ (see Fig. 2c). Again, only for the extreme conditions with $v_{i}>250 \mathrm{~km} \mathrm{~s}^{-1}$ (within 3 min intervals) can one observe the distinct increase of fluxes for all energies. This increase cannot be due to the faster motion of whole ion distribution because energy corresponding to particle bulk velocity $m_{p} v_{i}^{2} f / 2<1-2 \mathrm{keV}$ is substantially smaller than energies of the considered ion population $(\in[20,600] \mathrm{keV})$. It is interesting to note that the increase of fluxes is almost independent on energy (compare data for $v_{i} \in[100,250] \mathrm{km} \mathrm{s}^{-1}$ and $v_{i}>250 \mathrm{~km} \mathrm{~s}^{-1}$ ). These results correlate well with data presented by Luo et al. (2014) for earthward plasma flows, where almost no variation of the spectral index with $v_{i}$ was found. However, for tailwarddirected bulk velocity, Luo et al. (2014) showed that the spectral index hardens with the increase of $v_{i}$. The latter results cannot be confirmed by our data.

To investigate the variation of spectrum with system parameters, we plot three 2-D maps with fluxes as functions of energy and $T_{i}, B_{z}, v_{i}$ (see Fig. 3). On the far right panel of Fig. 3, we also show the scale of the ion kinetic energy $v_{i}^{2} m_{p} / 2$ calculated with the proton mass $m_{p}$. Fluxes increase with $T_{i}$ in the almost whole energy range $E \in[20,500] \mathrm{keV}$. The most pronounced increase of fluxes can be found for $T_{i} \in[1,5] \mathrm{keV}$. The increase of $B_{z}$ does not influence fluxes until $B_{z} \sim 5 \mathrm{nT}$. For $B_{z}>5 \mathrm{nT}$, one can find some increase of fluxes for energies $E<200 \mathrm{keV}$. The increase of $v_{i}$ also results in the increase of fluxes.

Figures 2 and 3 show that high-energy ion spectra generally depend on the ion temperature $T_{i}$. Thus, it seems interesting to plot energy spectra normalized on $T_{i}$. This normalized spectra clearly show the double power-law structure (see Figs. 3, 4). We observe the remaining part of the thermal core for $E<10-50 \mathrm{keV}$ (this boundary is different for different ranges of $T_{i}$ ) and a power-law tail for $E>10-50 \mathrm{keV}$. The main part of the spectrum with a large $E$ should be formed by the ion acceleration in the magnetotail. This population of high-energy ions is well separated from the thermal population and corresponds to the following phase-space-density variation with energy $f \sim\left(E / T_{i}\right)^{-3.8}$ to $f \sim\left(E / T_{i}\right)^{-4.2}$. We consider below a possible mechanism of the generation 


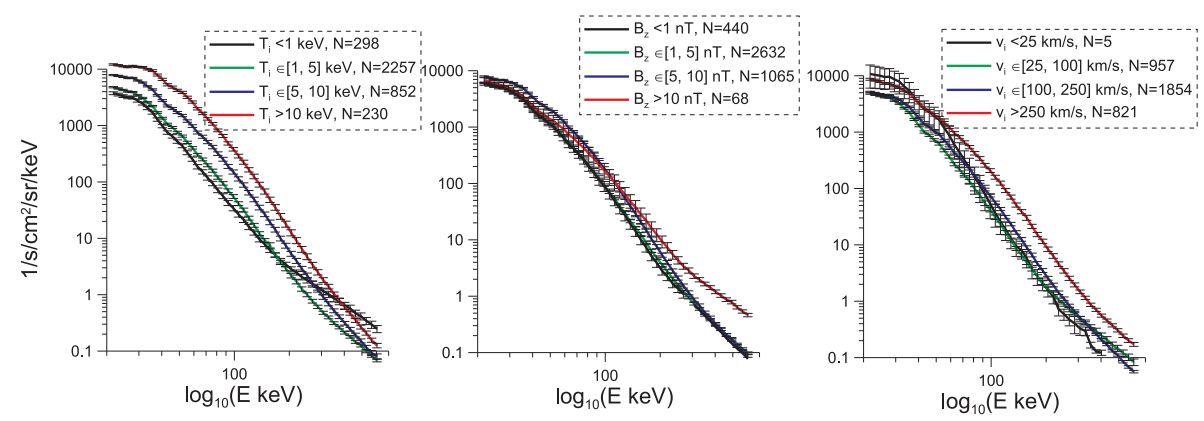

Figure 2. Averaged spectra of ions for different ranges of system parameters.
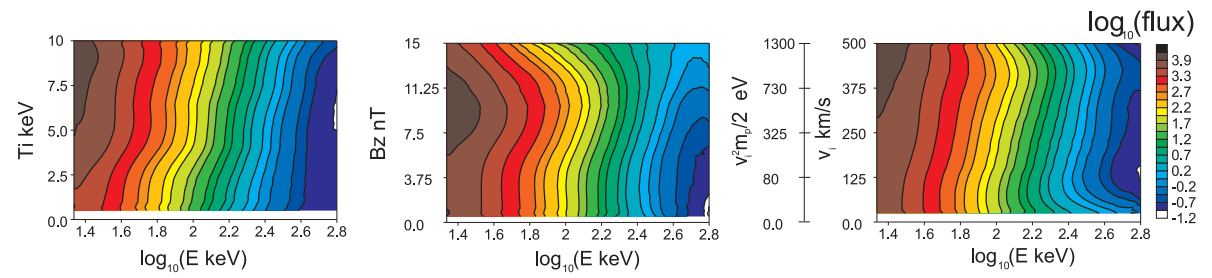

Figure 3. 2-D maps of ion fluxes (measured in $\left.\left(\mathrm{s} \mathrm{cm}^{2} \mathrm{sr} \mathrm{keV}\right)^{-1}\right)$.

of such a population. It is also interesting to note that, for small $T_{i}$, we observe more ions with very high relative energies $E / T_{i}>100$ than for large $T_{i}$. These ions form the flattened energy tail.

Figure 4 clearly shows that the relation $E^{*} / T_{i} \approx \gamma+1$ proposed by Sarris et al. (1981) for the energy $E^{*}$ of the spectrum knee is well satisfied only for particles with high temperatures $\left(T_{i}>5 \mathrm{keV}\right)$. For averaged conditions when all temperatures $T_{i}>0.5 \mathrm{keV}$ are taken into account, we get $E^{*} / T_{i} \approx 40 \gg \gamma+1$. Thus, we cannot consider the energy distribution in the whole energy range $E \in[20,500] \mathrm{keV}$ as a distribution of some single population. The normalization of energy on ion temperature modifies the distribution substantially for different $T_{i}$, but the slope of power-law tail does not depend on $T_{i}$ ( $\gamma$ varies from 3.8 to 4.2 ). It seems that the tail of the energy distribution is formed independently on the thermal core of ion population.

In Fig. 5, we show distribution of energetic fluxes along the dawn-dusk coordinate $Y$. There is a statistical gap around $Y \sim 0$ which can cause the decrease of fluxes in this region. One can also observe the general increase of fluxes for almost all energies at the dusk flank around $Y \sim-10 R_{\mathrm{E}}$. However, in the deep flanks, $|Y|>15 R_{\mathrm{E}}$ fluxes decrease. The latter effect can be due to particle losses through the flank magnetopause. We also observe a localized maximum of fluxes at $Y \sim-10 R_{\mathrm{E}}$ (similar maximum was found for ion density by Lennartsson and Shelley, 1986).

To illustrate our conclusion derived from Fig. 4 about the role of $T_{i}$ in the separation between thermal and high-energy populations, we plot data for two events with substantially different $T_{i}$ (see Fig. 6). In both cases, the spacecraft was

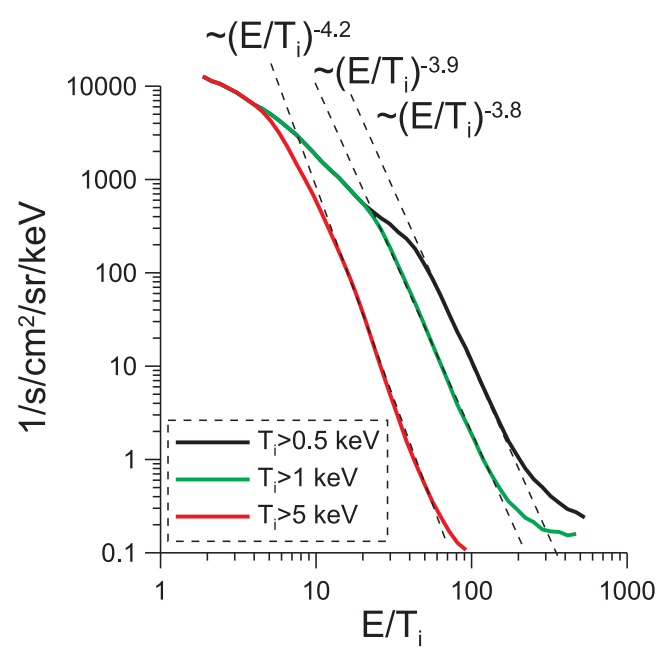

Figure 4. Averaged ion spectrum with the energy normalized on the ion temperature $T_{i}$.

located near the neutral plane $\left|B_{x}\right|<10 \mathrm{nT}$, while activity level was moderate with $V_{x} \sim 100-300 \mathrm{~km} \mathrm{~s}^{-1}$. There are $B_{x}$ fluctuations for the second event (top right panel of Fig. 6). We assume that these are vertical fluctuations of the magnetotail current sheet induced by plasma flows (see review Zelenyi et al., 2014, and references therein). For the first case, we have $T_{i} \sim 1-3 \mathrm{keV}$. Corresponding ion spectra have double structure with the knee around $30-40 \mathrm{keV}$. For the second case, the ion temperature is $\sim 8-9 \mathrm{keV}$ and the knee of the energy spectra is located at $\sim 70-80 \mathrm{keV}$. We can also mention that the averaged slope of spectra of high-energy populations are similar for both events. These slopes vary 

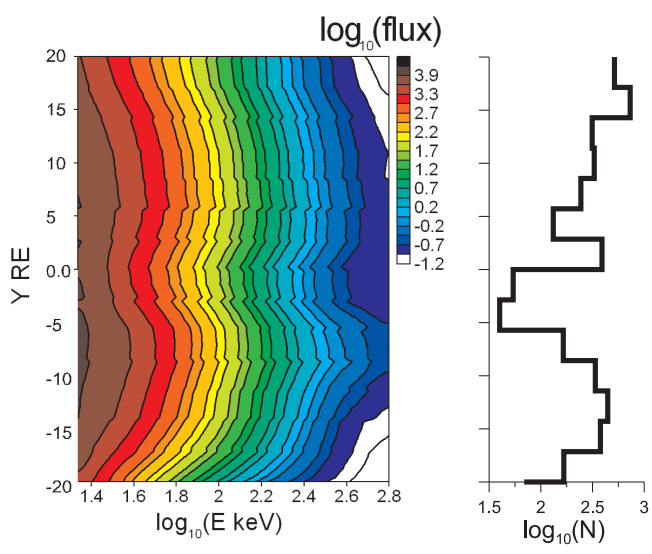

Figure 5. 2-D map of ion fluxes (measured in $\left(\mathrm{s} \mathrm{cm}^{2} \mathrm{sr} \mathrm{keV}^{-1}\right)$ as a function of $Y$ coordinate. The right panel shows the number of events $(N)$ for a given $Y$ coordinate.

between -4.8 up to -4.1 (see Fig. 6) and are close to the statistical data shown in Fig. 4. It seems that the spectrum slope of the non-thermal (high-energy) population is almost independent of the plasma temperature, while the distribution of the thermal core is strongly controlled by $T_{i}$. The increase of $T_{i}$ by three to four times results in the shift of the spectrum knee energy from $\sim 30$ to $70 \mathrm{keV}$. Variations of $T_{i}$ correspond to large-scale quasi-stationary processes (convection, etc.). Thus, we can conclude that the formation of the high-energy population (slope of the spectrum) does not directly depend on large-scale processes (slopes are similar for both events), while these processes can be responsible for the heating of the thermal plasma. In this case, the increase of $T_{i}$ corresponds to the increase of the amount of particles which can undergo the acceleration up to high energies.

\section{Model of ion acceleration}

In this section, we describe the analytical model of the formation of spectra of high-energy ions in the magnetotail. We consider small-scale transient processes corresponding to localized perturbations of magnetic and electric fields. Our model is based on the following concepts: (1) there is the almost unperturbed magnetotail current sheet with $B_{x}$ growing linearly with $z ;(2)$ the magnetic-field component $B_{z}$ has a substantially perturbed profile along the $X$ axis within the domain $\left|x-x^{*}\right|<L_{x}$, where $L_{x}$ is the spatial scale of the localization of $B_{z}$ perturbations; (3) there is the burst of the electric field $E_{y}(t)$ with the almost uniform distribution within $\left|x-x^{*}\right|<L_{x}$. This conception assumes that we consider small-scale (but very fast) perturbations of electromagnetic field which contribute more to electric-field bursts, while magnetic fields are weakly perturbed (the similar model of ion acceleration due to localized current disruptions was proposed by Lutsenko et al., 2008). We do not consider large-scale dipolarization events or quasi-stationary magnetic reconnections. Of course, these global processes contribute to the charged particle acceleration (see dependence of fluxes on geomagnetic conditions in Haaland et al., 2010). However, we assume that the main part of spectra, existing even in quiet time, can be formed mainly by small-scale transient perturbations. Such perturbations should not be very powerful, but should effectively accelerate small populations of particles up to high energies (see, e.g., Grigorenko et al., 2013).

To describe ion acceleration, we introduce a quite general distribution of electromagnetic fields in the magnetotail in the vicinity of the transient event: $B_{x}=B_{x 0} \cdot\left(z / L_{z}\right)$, $B_{z}=B_{z 0} \cdot\left(x / L_{x}\right)^{\alpha}>0, \boldsymbol{E}=E_{0}(t) e_{y}$, where $\alpha=$ const defines the profile of $B_{z}(x)$ component along $X$ axis $(\alpha=0$ for unperturbed $B_{z}, \alpha=1$ for the classical $X$ line, $\alpha>1$ for non-linear magnetic-field perturbation with the strong gradient $\mathrm{d} B_{z} / \mathrm{d} x$ ). This model can describe the distribution of the magnetic field close to the neutral plane (i.e., $|z|<L_{z}, L_{z}$ is the current sheet thickness). The dependence $B_{z} \sim x^{\alpha}$ is taken to describe the perturbation of the $B_{z}$ component inside the domain $\left|x-x^{*}\right|<L_{x}$, where the transient $E_{y}$ burst occurs. Equations of motions of ion with the mass $m$ and the charge $q$ in such fields can be written as

$$
\begin{aligned}
\ddot{x} & =\frac{q}{m c} B_{z 0}\left(x / L_{x}\right)^{\alpha} v_{y} \\
\ddot{z} & =-\frac{q}{m c} B_{x 0}\left(z / L_{z}\right) v_{y} \\
v_{y} & =v_{y 0}+\frac{q}{m} \int_{0}^{t} E_{y}\left(t^{\prime}\right) \mathrm{d} t^{\prime}-\frac{q}{m c} A_{y}(x, z),
\end{aligned}
$$

where $A_{y}(x, z)$ is the vector potential component. We are mainly interested in high energy particles which gain energy as $v_{y} \sim \int E_{y}(t) \mathrm{d} t \gg v_{y 0}$. Thus, we can omit both term $\sim A_{y}$ and the initial velocity $v_{y 0}$ in the last equation of system (1). Then, system (1) can be rewritten as

$$
\begin{aligned}
& \ddot{x}=\frac{q^{2}}{m^{2} c} B_{z 0}\left(x / L_{x}\right)^{\alpha} \int_{0}^{t} E_{y}\left(t^{\prime}\right) \mathrm{d} t^{\prime} \\
& \ddot{z}=-\frac{q^{2}}{m^{2} c} B_{x 0}\left(z / L_{z}\right) \int_{0}^{t} E_{y}\left(t^{\prime}\right) \mathrm{d} t^{\prime} .
\end{aligned}
$$

The second equation of system (2) describes $z$ oscillations, while the first equation shows that the $x$ coordinate grows with time. Thus, particles can spend only a limited time interval in the close vicinity of the $x \sim x^{*}$ region. This instability of the particle motion (i.e., $|x|$ growth) determines the final energy distribution. To describe charged particle acceleration in such a system, we introduce the simple approximation for the electric field $E_{y}=E_{0}\left(t / t_{0}\right)^{\delta}$, where $t_{0}=$ const is the scale of $E_{y}$ growth. The first equation of system (2) takes 

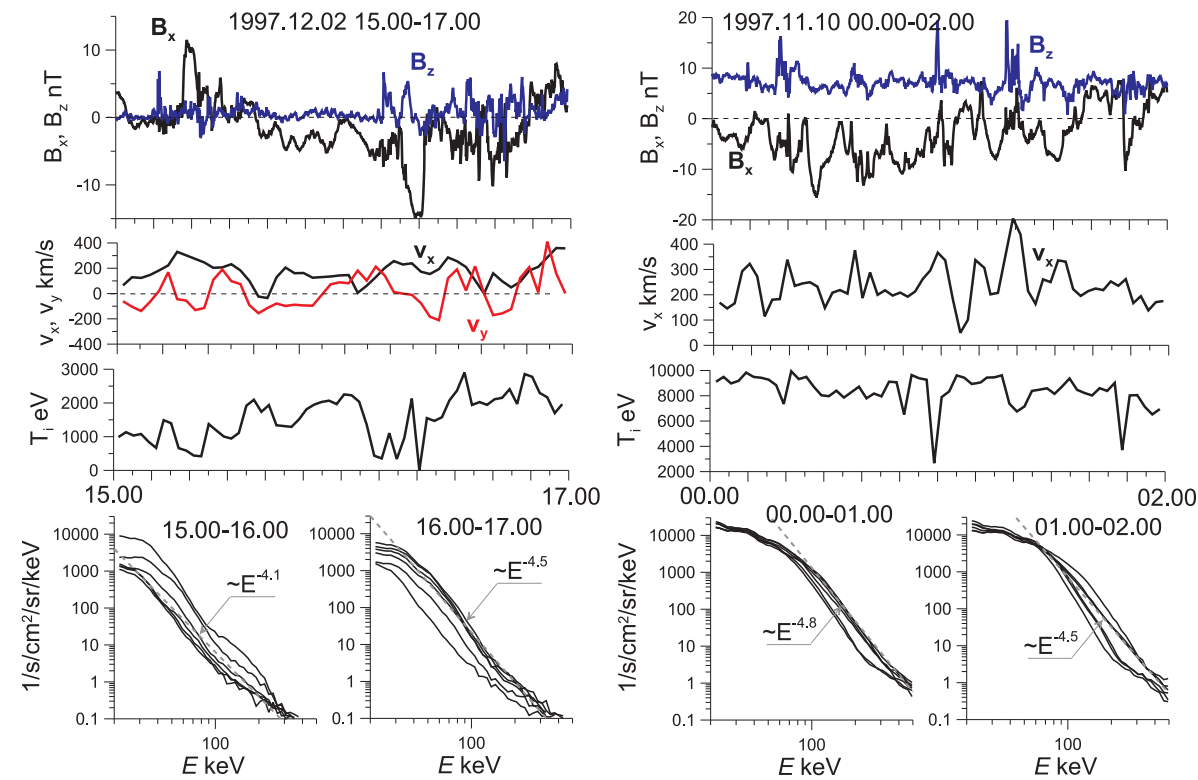

Figure 6. Two cases of observations of high-energy ion spectra in the magnetotail. Top panels show two components of the magnetic field in the GSM coordinate system. Middle panels show ion bulk velocities and temperatures $\left(v_{y}\right.$ component was measured only for the event shown in the left panels). Bottom panels show ion-energy spectra: each panel shows six spectra averaged over 10 min of observations.

a form

$\ddot{x}=\frac{\Omega_{0}^{2} v_{D} t_{0}}{1+\delta}\left(x / L_{x}\right)^{\alpha}\left(t / t_{0}\right)^{\delta+1}$,

where $\Omega_{0}=q B_{z 0} / m c$ and $v_{D}=c E_{0} / B_{z 0}$. We introduce dimensionless variables $X=x / L_{x}, \tau=t / T$, where $T=$ $t_{0}\left((1+\delta) L_{x} / \Omega_{0}^{2} v_{D} t_{0}^{3}\right)^{1 /(3+\delta)}$ :

$\frac{d^{2} X}{d \tau^{2}}=X^{\alpha} \tau^{\delta+1}$.

We consider particles with small initial velocities $\dot{x}(0)=0$. Higher energies can be gained by particles with $x(0)=x_{0} \sim$ $x^{*}$. With this initial condition, the solution of Eq. (4) can be written as

$X=x_{0} Y\left(x_{0}^{(\alpha-1) /(\delta+3)} \tau\right)$,

where $Y(s)$ is a solution of the following equation:

$\frac{d^{2} Y}{d s^{2}}=Y^{\alpha} s^{\delta+1}$

$Y(0)=1, \quad \mathrm{~d} Y /\left.\mathrm{d} s\right|_{s=0}=0$

and $s=x_{0}^{(\alpha-1) /(\delta+3)} \tau$. The solution of Eq. (6) is singular with the asymptote

$Y \sim\left(s_{*}-s\right)^{-\frac{2}{\alpha-1}}$,

where $s_{*}=$ const. Thus, the relation between the initial particle position $x_{0}$ and the time interval of the particle acceleration $\tau$ is determined by the equation

$L_{x} \sim x_{0}\left(s_{*}-x_{0}^{\frac{\alpha-1}{3+\delta} \tau}\right)^{\frac{-2}{\alpha-1}}$.
For the most energetic particles, we have, from Eq. (8), $x_{0} \sim \tau^{-\gamma}$ with $\gamma=(3+\delta) /(\alpha-1)$. Thus, particles are accelerated as $v_{y} \sim(q / m) \int E_{y}(t) \mathrm{d} t \sim \Omega_{0} v_{D} t_{0}\left(t / t_{0}\right)^{\delta+1} /(\delta+1)$. We can write the expression for the particle energy as a function of time:

$W \approx \frac{1}{2} m v_{y}^{2} \approx \frac{m v_{D}^{2}}{2} w_{0} \tau^{2 \delta+2}$,

where constant $w_{0}$ is

$w_{0}=(\delta+1)^{-4 /(3+\delta)} \frac{\left(L_{x} \Omega_{0} / v_{D}\right)^{(2 \delta+2) /(3+\delta)}}{\left(\Omega_{0} t_{0}\right)^{4 \delta /(3+\delta)}}$.

We assume that particles are distributed uniformly at the interval $x_{0} \in\left[x^{*}-L_{x}, x^{*}+L_{x}\right]$ and write the expression for the final energy distribution

$$
\begin{aligned}
f(W) & =f\left(x_{0}\right)\left|\frac{\mathrm{d} x_{0}}{\mathrm{~d} \tau}\right|\left|\frac{\mathrm{d} W}{\mathrm{~d} \tau}\right|^{-1} \\
& \sim \frac{1}{\tau^{\gamma+2 \delta+2}} \sim\left(\frac{2 W}{w_{0} m v_{D}^{2}}\right)^{-\lambda},
\end{aligned}
$$

where $\left|\mathrm{d} x_{0} / \mathrm{d} \tau\right| /|\mathrm{d} W / \mathrm{d} \tau|$ transforms the initial distribution $f\left(x_{0}\right)$ of particles in space into the final energy distribution $f(W)$ with the slope

$\lambda=1+\frac{1}{2} \frac{3+\delta}{(\alpha-1)(1+\delta)}$.

For the simple case of the constant electric field $\delta=0$, we have $\lambda=1+1.5 /(\alpha-1)$. Even a small deviation of $B_{z}$ dependence on $x$ from the linear one (i.e., $\alpha-1<1$ ) gives us 
a power-law distribution. For example, to get $\lambda \in[3.5,5]$, one needs to take $\alpha \in[8 / 5,11 / 8] \approx[1.6,1.4]$. In case of linear dependence of $B_{z}$ on $x$ (i.e., $\alpha=1$, like in $X$ line), we should obtain the well-known exponential spectrum with $f \sim \exp (-W)$ (Bulanov and Sasorov, 1976; Birn et al., 2012). Equation (12) shows that the spectrum slope is very sensitive to the electric-field growth rate $\delta$ and the factor of the magnetic field non-linearity $\alpha$. Both these factors cannot be derived directly from the single spacecraft observations because, to determine the temporal profile of the electric field $E_{y}$ and the spatial profile of the magnetic field $B_{z}$, one needs to separate spatial and temporal evolutions in transient processes. Thus, a direct comparison of model predictions and spacecraft observation is impossible. The main idea of the proposed model is to show that it is enough to assume the non-linearity of $B_{z}$ profiles and transient nature of the process to obtain the power-law energy spectrum of accelerated ions. We discuss in the next section the relationship between input parameters of our model and properties of different transient processes observed in the magnetotail.

The factor $w_{0} m v_{D}^{2}$ determines the typical energy gained by particles in the course of transient acceleration. For the constant electric field $\delta=0$, we can estimate this energy as $w_{0} m v_{D}^{2}=e E_{y} L_{x}\left(L_{x} \Omega_{0} / v_{D}\right)^{-1 / 3}$. For a small-scale process with $L_{x} \sim 1000 \mathrm{~km}$ and the electric-field amplitude typical for transients $E_{y} \sim 10-100 \mathrm{mV} \mathrm{m}^{-1}$ (Wygant et al., 2005; Retinò et al., 2008; Nakamura et al., 2009; Khotyaintsev et al., 2011), one has $w_{0} m v_{D}^{2} \sim 10-100 \mathrm{keV}$. Moreover, $w_{0}$ grows with $\delta$ rapidly and the non-stationary electric field $E_{y} \sim t^{\delta}$ can be even more effective for the particle acceleration.

\section{Discussion}

In this paper, we have shown that variations of $B_{z}$ and $v_{i}$ do not substantially influence the shape of spectra of highenergy ions. However, we observe that the increase of highenergy ion fluxes corresponds with $B_{z}$ and $v_{i}$ growth (see Fig. 2). It seems that processes characterized by enhanced $B_{z}$ and $v_{i}$ (like large-scale dipolarizations or BBFs) can have an influence on the total amount of accelerated particles, but do not determine the slope of energy spectra. We found a strong correlation between fluxes of high-energy ions and the temperature of thermal ions: the larger the $T_{i}$, the more particles from the thermal core of the distribution can be accelerated to high energies and contribute to the large-energy tail of the distribution. Thus, observed correlation between fluxes and $B_{z}$ (or $v_{i}$ ) can be explained by the heating of plasma (increase of $T_{i}$ ) due to dipolarization and enhanced convection. Indeed, many studies (e.g., Baumjohann et al., 1991; Wang et al., 2009; Kissinger et al., 2012) demonstrated that ion temperature $T_{i}$ grows as $B_{z}$ (or $v_{i}$ ) grows. Therefore, the formation of spectra of high-energy ions should be explained by some mechanism which does not involve a large-scale transformation of the magnetic-field configuration. We suggest that small-scale transient bursts of the electric field can be considered as the main source of ion acceleration up to high energies. Such transient processes do not require the magnetotail reconfiguration and can operate within spatially localized regions with scales $\sim 1000 \mathrm{~km}$. There are several candidates which play the role of these transients (see reviews by Baumjohann et al., 2007; Sharma et al., 2008). Here, we would like to mention dipolarization fronts (Runov et al., 2009, 2011), small-scale reconnections (Wygant et al., 2005; Retinò et al., 2008), and plasma jet braking (Nakamura et al., 2009, 2013). All of these processes are related to each other (Sitnov et al., 2009, 2013; Runov et al., 2012; Fu et al., 2013a). Although these processes correspond to the local increase of $B_{z}$ and $v_{i}$, they cannot provide substantial variations of $B_{z}$ and $v_{i}$ on a timescale larger than $\sim 1 \mathrm{~min}$. Thus, we cannot recognize signatures of these processes in our statistics with $\sim 3 \mathrm{~min}$ averaging. Ion acceleration induced by these transient processes can be explained by our model of the spectrum formation. To apply our mode we need to fulfill two basic requirements.

1. There should be the non-linear variation of the magnetic-field perturbation $B_{z}$ with $x$ (i.e., $\alpha>1$ ). The strong gradient of $B_{z}$ is a characteristic feature of the dipolarization fronts. Thus, $B_{z}$ perturbation grows nonlinearly with $x$. A small-scale reconnection is often accompanied by a strong perturbation of $B_{z}$, possibly related to following formation of dipolarization fronts (Sitnov et al., 2013; Fu et al., 2013a). Thus, we can expect that, for the transient reconnection, the variation of $B_{z}$ with $x$ is non-linear (e.g., at the outflow regions, where soliton-like $B_{z}$ perturbations are generated, see Heyn and Semenov, 1996; Longcope and Priest, 2007). The flow-braking process results in formation of shock waves or non-linear $B_{z}$ perturbations (Nakamura et al., 2009; Zieger et al., 2011). Therefore, for all three types of transient processes, the expected variation of $B_{z}$ with $x$ may have non-linear character needed for the application of our model.

2. The second requirement is the presence of bursts of the electric field in the region of the $B_{z}$ perturbation. Again, such bursts are always observed in the vicinity of dipolarization fronts (e.g., Runov et al., 2011; Khotyaintsev et al., 2011), in the reconnection region (Wygant et al., 2005; Retinò et al., 2008), and in the flow-braking region (Nakamura et al., 2009, 2013). Thus, the second requirement of our model is also satisfied. As a result, we can explain observed power-law ion spectra by a proposed mechanism of ion acceleration.

It is also important to discuss the scale $L_{y}$ of the acceleration region along the dawn-dusk direction. For various transient processes, this scale can reach few earth radii. Thus, it is substantially larger than $L_{x}$ scale. For example, 
multi-spacecraft measurements of dipolarization fronts show that, for these transient structures, we have $L_{y} \sim 5000$ $15000 \mathrm{~km}$ (Nakamura et al., 2004; Liu et al., 2013). Thus, the typical amplitude of the electric field necessary to accelerate particles up to $100 \mathrm{keV}$ is about $5-20 \mathrm{mV} \mathrm{m}^{-1}$ in agreement with spacecraft observations (Khotyaintsev et al., 2011; Runov et al., 2012; Fu et al., 2013a). The same spatial scale $L_{y}$ and electric-field amplitudes are typical for the flowbraking process as well (e.g., Nakamura et al., 2009, 2013). The scale $L_{y}$ of the transient reconnection is less known. However, comparison of spacecraft observations and analytical models (Alexandrova et al., 2012; Nakamura et al., 2012) gives similar estimates for $L_{y}$ as values obtained for dipolarization fronts, while the electric-field amplitude in the reconnection region can reach $10-100 \mathrm{mV} \mathrm{m}^{-1}$ (Wygant et al., 2005; Retinò et al., 2008). Thus, rough estimates show that the proposed scenario of the ion acceleration up to $100 \mathrm{keV}$ is in agreement with the observed spatial localization of transient processes.

Using average spectra from Fig. 4, one can estimate an impact of the high-energy ion population. Substantial influence of high-energy population on the current sheet configuration is possible if the contribution of this population to the plasma pressure is comparable with the pressure of thermal ions. Such a specific situation could be realized in the vicinity of shock waves (Wang et al., 2008; Florinski, 2009), but never was mentioned before for the magnetotail. We choose the energy spectrum obtained for hot plasma (with $T_{i}>5 \mathrm{keV}$, see Fig. 4) and approximate it by the powerlaw function $f_{\text {hot }} \sim n_{\text {hot }}\left(E / T_{i}\right)^{-\gamma}$ for $E / T_{i} \in[5,100]$. Here, constant $n_{\text {hot }}$ can be determined by matching $f_{\text {hot }}$ distribution with the thermal distribution $f_{\text {th }}=n_{\text {th }} \exp \left(-E / T_{i}\right)$ approximated by the Maxwell function: $n_{\text {hot }}=n_{\text {th }} 5^{\gamma} e^{-5}$. The ratio of pressures of high-energy and thermal populations can be written as $p_{\text {hot }} / p_{\text {th }} \approx 5^{5 / 2} e^{-5} /(\gamma-5 / 2)$. For $\gamma \in[4,6]$, we have $p_{\text {hot }} / p_{\text {th }} \in[0.1,0.25]$. Thus, for a hot-plasma sheet with $T_{i}>5 \mathrm{keV}$, the high-energy ion population can principally provide up to $25 \%$ of the plasma pressure. A similar conclusion was derived before from the inconsistency of the thermal-plasma pressure and the magnetic-field pressure in current sheets (Runov et al., 2006). Although $25 \%$ is a substantial value to take the high-energy population as the important ingredient of the magnetotail plasmas into account, we should point out that this is the estimate of maximum possible contribution and that this estimate is only valid for the large temperature of thermal ions. Contributions of the high-energy ion population to the ion density and the electric current are even smaller (Artemyev et al., 2009a).

It is interesting to note one important detail of the proposed model of the ion acceleration. We have obtained the dependence of the typical energy $W \sim m v_{D}^{2} w_{0}$ of accelerated ions on the ion mass $m: W \sim m^{(3 \delta+1) /(3+\delta)}$. For almost stationary electric field $\delta=0$, we have the dependence $W \sim m^{1 / 3}$ derived before for the $X$ line model (Bulanov and
Sasorov, 1976; Divin et al., 2010). This is relatively weak dependence. For example, oxygen ions are accelerated more effectively than protons, only by factor $\sim 2.5$. However, already for $\delta=1$ (i.e., linearly growing $E_{y}$ ), we have $W \sim m$, and heavy ions are accelerated much more effective than protons. Moreover, if we assume that electric-field bursts are extremely fast (i.e., $E_{y} \sim e^{t}, \delta \rightarrow \infty$ ), we obtain ultra-effective acceleration of heavy ions with $W \sim m^{3}$. Thus, the proposed model of ion acceleration could explain more effective energization of heavy ions in the earth's magnetosphere (e.g., Kronberg et al., 2012) and in solar corona (see Zimbardo, 2011; Artemyev et al., 2014, and references therein).

\section{Conclusions}

In this paper, we have investigated the energy distributions for ions with $E \in[20,600] \mathrm{keV}$, observed by Interball-tail in the earth's magnetotail. We have shown that spectra can be separated into two parts: the thermal core and the highenergy tail with $f \sim\left(E / T_{i}\right)^{-\gamma}$ with $\gamma \in[4,5]$. There is only a weak dependence of high-energy ion population on $B_{z}$ and $v_{i}$ averaged amplitudes. The temperature of the thermal ion population controls the amplitudes of fluxes, but does not influence the spectrum slope. Thus, we have concluded that mechanisms responsible for ion acceleration up to high energies do not have a substantial influence on the thermal ion population. Moreover, mechanisms of thermal ion heating (dipolarizations, large-scale reconnection, convection, etc.) do not input significantly to the formation of the high-energy ion population. We have proposed the simple and relatively general model of formation of the high-energy ion population with the power-law spectrum. This model assumes that the main acceleration up to high energies $E>50 \mathrm{keV}$ is provided by small-scale fast bursts of the electric field, occurring due to various transients in the magnetotail.

Acknowledgements. Authors would like to acknowledge Interball instrument teams ASPI/MIF-M, CORALL, ELECTRON and DOK2 for excellent data. Work was supported by the Russian Scientific Fund (project no. 14-12-00824).

Topical Editor V. Fedun thanks two anonymous referees for their help in evaluating this paper.

\section{References}

Alexandrova, A., Nakamura, R., Semenov, V. S., Kubyshkin, I. V., Apatenkov, S., Panov, E. V., Korovinskiy, D., Biernat, H., Baumjohann, W., Glassmeier, K.-H., and McFadden, J. P.: Remote estimation of reconnection parameters in the Earth's magnetotail: model and observations, Ann. Geophys., 30, 17271741, doi:10.5194/angeo-30-1727-2012, 2012.

Angelopoulos, V., Baumjohann, W., Kennel, C. F., Coronti, F. V., Kivelson, M. G., Pellat, R., Walker, R. J., Luehr, H., and Paschmann, G.: Bursty bulk flows in the inner 
central plasma sheet, J. Geophys. Res., 97, 4027-4039, doi:10.1029/91JA02701, 1992.

Angelopoulos, V., Kennel, C. F., Coroniti, F. V., Pellat, R., Spence, H. E., Kivelson, M. G., Walker, R. J., Baumjohann, W., Feldman, W. C., and Gosling, J. T.: Characteristics of ion flow in the quiet state of the inner plasma sheet, Geophys. Res. Lett., 20, 17111714, doi:10.1029/93GL00847, 1993.

Angelopoulos, V., Runov, A., Zhou, X. Z., Turner, D. L., Kiehas, S. A., Li, S. S., and Shinohara, I.: Electromagnetic Energy Conversion at Reconnection Fronts, Science, 341, 1478-1482, doi:10.1126/science.1236992, 2013.

Artemyev, A., Vainchtein, D., Neishtadt, A., and Zelenyi, L.: Resonant acceleration of charged particles in the presence of random fluctuations, Phys. Rev. E, 84, 046213, doi:10.1103/PhysRevE.84.046213, 2011.

Artemyev, A. V., Petrukovich, A. A., Zelenyi, L. M., Nakamura, R., Malova, H. V., and Popov, V. Y.: Thin embedded current sheets: Cluster observations of ion kinetic structure and analytical models, Ann. Geophys., 27, 4075-4087, doi:10.5194/angeo27-4075-2009, 2009a.

Artemyev, A. V., Zelenyi, L. M., Malova, H. V., Zimbardo, G., and Delcourt, D.: Acceleration and transport of ions in turbulent current sheets: formation of non-maxwelian energy distribution, Nonlin. Processes Geophys., 16, 631-639, doi:10.5194/npg-16631-2009, 2009b.

Artemyev, A. V., Lutsenko, V. N., and Petrukovich, A. A.: Ion resonance acceleration by dipolarization fronts: analytic theory and spacecraft observation, Ann. Geophys., 30, 317-324, doi:10.5194/angeo-30-317-2012, 2012a.

Artemyev, A. V., Petrukovich, A. A., Nakamura, R., and Zelenyi, L. M.: Adiabatic electron heating in the magnetotail current sheet: Cluster observations and analytical models, J. Geophys. Res., 117, A06219, doi:10.1029/2012JA017513, 2012 b.

Artemyev, A. V., Hoshino, M., Lutsenko, V. N., Petrukovich, A. A., Imada, S., and Zelenyi, L. M.: Double power-law spectra of energetic electrons in the Earth magnetotail, Ann. Geophys., 31, 91-106, doi:10.5194/angeo-31-91-2013, 2013.

Artemyev, A. V., Zimbardo, G., Ukhorskiy, A. Y., and Fujimoto, M.: Preferential acceleration of heavy ions in the reconnection outflow region. Drift and surfatron ion acceleration, Astron. Astrophys., 562, A58, doi:10.1051/0004-6361/201322462, 2014.

Ashour-Abdalla, M., Berchem, J. P., Buechner, J., and Zelenyi, L. M.: Shaping of the magnetotail from the mantle Global and local structuring, J. Geophys. Res., 98, 5651-5676, doi:10.1029/92JA01662, 1993.

Ashour-Abdalla, M., Leboeuf, J. N., Schriver, D., Bosqued, J., Cornilleau-Wehrlin, N., Sotnikov, V., Marchaudon, A., and Fazakerley, A. N.: Instabilities driven by ion shell distributions observed by Cluster in the midaltitude plasma sheet boundary layer, J. Geophys. Res., 111, A10223, doi:10.1029/2005JA011490, 2006.

Ashour-Abdalla, M., El-Alaoui, M., Goldstein, M. L., Zhou, M., Schriver, D., Richard, R., Walker, R., Kivelson, M. G., and Hwang, K.-J.: Observations and simulations of non-local acceleration of electrons in magnetotail magnetic reconnection events, Nat. Phys., 7, 360-365, doi:10.1038/nphys1903, 2011.

Baker, D. N., Hones Jr., E. W., Higbie, P. R., Belian, R. D., and Stauning, P.: Strong electron pitch angle diffusion ob- served at geostationary orbit, Geophys. Res. Lett., 6, 205-208, doi:10.1029/GL006i003p00205, 1979.

Baumjohann, W., Paschmann, G., and Luehr, H.: Characteristics of high-speed ion flows in the plasma sheet, J. Geophys. Res., 95, 3801-3809, doi:10.1029/JA095iA04p03801, 1990a.

Baumjohann, W., Sachsenweger, D., and Moebius, E.: Suprathermal ion fluxes in the plasma sheet, Geophys. Res. Lett., 17, 275278, doi:10.1029/GL017i003p00275, 1990b.

Baumjohann, W., Paschmann, G., Hagai, T., and Luehr, H.: Superposed epoch analysis of the substorm plasma sheet, J. Geophys. Res., 96, 11605, doi:10.1029/91JA00775, 1991.

Baumjohann, W., Roux, A., Le Contel, O., Nakamura, R., Birn, J., Hoshino, M., Lui, A. T. Y., Owen, C. J., Sauvaud, J.-A., Vaivads, A., Fontaine, D., and Runov, A.: Dynamics of thin current sheets: Cluster observations, Ann. Geophys., 25, 13651389, doi:10.5194/angeo-25-1365-2007, 2007.

Birn, J., Artemyev, A. V., Baker, D. N., Echim, M., Hoshino, M., and Zelenyi, L. M.: Particle acceleration in the magnetotail and aurora, Space Sci. Rev., 173, 49-102, doi:10.1007/s11214-0129874-4, 2012.

Bosqued, J. M., Ashour-Abdalla, M., El Alaoui, M., Peroomian, V., Zelenyi, L. M., and Escoubet, C. P.: Dispersed ion structures at the poleward edge of the auroral oval: Low-altitude observations and numerical modeling, J. Geophys. Res., 98, 19181, doi:10.1029/93JA01143, 1993.

Bulanov, S. V. and Sasorov, P. V.: Energy spectrum of particles accelerated in the neighborhood of a line of zero magnetic field, Soviet Astronomy, 19, 464-468, 1976.

Cao, J., Duan, A., Reme, H., and Dandouras, I.: Relations of the energetic proton fluxes in the central plasma sheet with solar wind and geomagnetic activities, J. Geophys. Res., 118, 7226-7236, doi:10.1002/2013JA019289, 2013.

Cao, J. B., Ma, Y. D., Parks, G., Reme, H., Dandouras, I., Nakamura, R., Zhang, T. L., Zong, Q., Lucek, E., Carr, C. M., Liu, Z. X., and Zhou, G. C.: Joint observations by Cluster satellites of bursty bulk flows in the magnetotail, J. Geophys. Res., 111, A04206, doi:10.1029/2005JA011322, 2006.

Christon, S. P., Mitchell, D. G., Williams, D. J., Frank, L. A., Huang, C. Y., and Eastman, T. E.: Energy spectra of plasma sheet ions and electrons from about $50 \mathrm{eV} / \mathrm{e}$ to about $1 \mathrm{MeV}$ during plamsa temperature transitions, J. Geophys. Res., 93, 2562 2572, doi:10.1029/JA093iA04p02562, 1988.

Christon, S. P., Williams, D. J., Mitchell, D. G., Frank, L. A., and Huang, C. Y.: Spectral characteristics of plasma sheet ion and electron populations during undisturbed geomagnetic conditions, J. Geophys. Res., 94, 13409-13424, doi:10.1029/JA094iA10p13409, 1989.

Christon, S. P., Williams, D. J., Mitchell, D. G., Huang, C. Y., and Frank, L. A.: Spectral characteristics of plasma sheet ion and electron populations during disturbed geomagnetic conditions, J. Geophys. Res., 96, 1-22, doi:10.1029/90JA01633, 1991.

Coroniti, F. V. and Kennel, C. F.: Can the ionosphere regulate magnetospheric convection?, J. Geophys. Res., 78, 2837 doi:10.1029/JA078i016p02837, 1973.

Daglis, I. A., Thorne, R. M., Baumjohann, W., and Orsini, S.: The terrestrial ring current: Origin, formation, and decay, Rev. Geophys., 37, 407-438, doi:10.1029/1999RG900009, 1999.

Divin, A., Markidis, S., Lapenta, G., Semenov, V. S., Erkaev, N. V., and Biernat, H. K.: Model of electron pressure anisotropy in the 
electron diffusion region of collisionless magnetic reconnection, Phys. Plasmas, 17, 122102, doi:10.1063/1.3521576, 2010.

Dolgonosov, M. S., Zimbardo, G., Perri, S., and Greco, A.: On the generation of ion beamlets in the magnetotail: Resonant acceleration versus stochastic acceleration, J. Geophys. Res., 118, 54455453, doi:10.1002/jgra.50490, 2013.

Dusenbery, P. B. and Lyons, L. R.: Ion diffusion coefficients from resonant interactions with broadband turbulence in the magnetotail, J. Geophys. Res., 94, 2484-2496, doi:10.1029/JA094iA03p02484, 1989.

Fan, C. Y., Gloeckler, G., and Hovestadt, D.: Energy spectra and charge states of $\mathrm{H}, \mathrm{He}$, and heavy ions observed in the earth's magnetosheath and magnetotail, Phys. Rev. Lett., 34, 495-498, doi:10.1103/PhysRevLett.34.495, 1975.

Florinski, V.: Pickup Ion Acceleration at the Termination Shock and in the Heliosheath, Space Sci. Rev., 143, 111-124, doi:10.1007/s11214-008-9451-z, 2009.

Fu, H. S., Cao, J. B., Khotyaintsev, Y. V., Sitnov, M. I., Runov, A., Fu, S. Y., Hamrin, M., André, M., Retinò, A., Ma, Y. D., Lu, H. Y., Wei, X. H., and Huang, S. Y.: Dipolarization fronts as a consequence of transient reconnection: In situ evidence, Geophys. Res. Lett., 40, 6023-6027, doi:10.1002/2013GL058620, 2013a.

Fu, H. S., Khotyaintsev, Y. V., Vaivads, A., Retinò, A., and André, M.: Energetic electron acceleration by unsteady magnetic reconnection, Nat. Phys., 9, 426-430, doi:10.1038/nphys2664, $2013 \mathrm{~b}$.

Galeev, A. A.: Reconnection in the magnetotail, Space Sci. Rev., 23, 411-425, doi:10.1007/BF00172248, 1979.

Greco, A., Veltri, P., Zimbardo, G., Taktakishvilli, A. L., and Zelenyi, L. M.: Numerical simulation of ion dynamics in the magnetotail magnetic turbulence: On collisionless conductivity, Nonlin. Processes Geophys., 7, 159-166, doi:10.5194/npg-7-1592000, 2000.

Greco, A., Perri, S., and Zimbardo, G.: Stochastic Fermi acceleration in the magnetotail current sheet: A numerical study, J. Geophys. Res., 115, 2203, doi:10.1029/2009JA014690, 2010.

Grigorenko, E. E., Hoshino, M., Hirai, M., Mukai, T., and Zelenyi, L. M.: "Geography" of ion acceleration in the magnetotail: Xline versus current sheet effects, J. Geophys. Res., 114, A03203, doi:10.1029/2008JA013811, 2009.

Grigorenko, E. E., Zelenyi, L. M., Dolgonosov, M. S., Artemiev, A. V., Owen, C. J., Sauvaud, J.-A., Hoshino, M., and Hirai, M.: Non-adiabatic Ion Acceleration in the Earth Magnetotail and Its Various Manifestations in the Plasma Sheet Boundary Layer, Space Sci. Rev., 164, 133-181, doi:10.1007/s11214-011-9858-9, 2011.

Grigorenko, E. E., Malova, H. V., Artemyev, A. V., Mingalev, O. V., Kronberg, E. A., Koleva, R., Daly, P. W., Cao, J. B., Sauvaud, J.A., Owen, C. J., and Zelenyi, L. M.: Current sheet structure and kinetic properties of plasma flows during a near-Earth magnetic reconnection under the presence of a guide field, J. Geophys. Res.-Space, 118, 3265-3287, doi:10.1002/jgra.50310, 2013.

Haaland, S., Kronberg, E. A., Daly, P. W., Fränz, M., Degener, L., Georgescu, E., and Dandouras, I.: Spectral characteristics of protons in the Earth's plasmasheet: statistical results from Cluster CIS and RAPID, Ann. Geophys., 28, 1483-1498, doi:10.5194/angeo-28-1483-2010, 2010.
Hasegawa, A., Mima, K., and Duong-van, M.: Plasma distribution function in a superthermal radiation field, Phys. Rev. Lett., 54, 2608-2610, doi:10.1103/PhysRevLett.54.2608, 1985.

Heyn, M. F. and Semenov, V. S.: Rapid reconnection in compressible plasma, Phys. Plasmas, 3, 2725-2741, doi:10.1063/1.871723, 1996.

Hoshino, M.: Electron surfing acceleration in magnetic reconnection, J. Geophys. Res., 110, A10215, doi:10.1029/2005JA011229, 2005.

Ipavich, F. M. and Scholer, M.: Thermal and suprathermal protons and alpha particles in the earth's plasma sheet, J. Geophys. Res., 88, 150-160, doi:10.1029/JA088iA01p00150, 1983.

Khotyaintsev, Y. V., Cully, C. M., Vaivads, A., André, M., and Owen, C. J.: Plasma Jet Braking: Energy Dissipation and Nonadiabatic Electrons, Phys. Rev. Lett., 106, 165001, doi:10.1103/PhysRevLett.106.165001, 2011.

Kirsch, E., Krimigis, S. M., Sarris, E. T., and Lepping, R. P.: Detailed study on acceleration and propagation of energetic protons and electrons in the magnetotail during substorm activity, J. Geophys. Res., 86, 6727-6738, doi:10.1029/JA086iA08p06727, 1981.

Kissinger, J., McPherron, R. L., Hsu, T.-S., and Angelopoulos, V.: Diversion of plasma due to high pressure in the inner magnetosphere during steady magnetospheric convection, J. Geophys. Res., 117, A05206, doi:10.1029/2012JA017579, 2012.

Kistler, L. M., Moebius, E., Klecker, B., Gloeckler, G., and Ipavich, F. M.: Spatial variations in the suprathermal ion distributions during substorms in the plasma sheet, J. Geophys. Res., 95, 1887118885, doi:10.1029/JA095iA11p18871, 1990.

Klimov, S., Romanov, S., Amata, E., Blecki, J., Büchner, J., Juchniewicz, J., Rustenbach, J., Triska, P., Woolliscroft, L. J. C., Savin, S., Afanas'yev, Yu., de Angelis, U., Auster, U., Bellucci, G., Best, A., Farnik, F., Formisano, V., Gough, P., Grard, R., Grushin, V., Haerendel, G., Ivchenko, V., Korepanov, V., Lehmann, H., Nikutowski, B., Nozdrachev, M., Orsini, S., Parrot, M., Petrukovich, A., Rauch, J. L., Sauer, K., Skalsky, A., Slominski, J., Trotignon, J. G., Vojta, J., and Wronowski, R.: ASPI experiment: measurements of fields and waves on board the INTERBALL-1 spacecraft, Ann. Geophys., 15, 514-527, doi:10.1007/s00585-997-0514-3, 1997.

Korovinskiy, D. B., Semenov, V. S., Erkaev, N. V., Divin, A. V., Biernat, H. K., and Möstl, U. V.: A 2.5-D electron Hall-MHD analytical model of steady state Hall magnetic reconnection in a compressible plasma, J. Geophys. Res., 116, A05219, doi:10.1029/2010JA015942, 2011.

Kronberg, E. A., Haaland, S. E., Daly, P. W., Grigorenko, E. E., Kistler, L. M., Fränz, M., and Dandouras, I.: Oxygen and hydrogen ion abundance in the near-Earth magnetosphere: Statistical results on the response to the geomagnetic and solar wind activity conditions, J. Geophys. Res., 117, A12208, doi:10.1029/2012JA018071, 2012.

Lennartsson, W. and Shelley, E. G.: Survey of 0.1 - to $16-\mathrm{keV} / \mathrm{e}$ plasma sheet ion composition, J. Geophys. Res., 91, 3061-3076, doi:10.1029/JA091iA03p03061, 1986.

Liu, J., Angelopoulos, V., Runov, A., and Zhou, X.-Z.: On the current sheets surrounding dipolarizing flux bundles in the magnetotail: The case for wedgelets, J. Geophys. Res., 118, 2000-2020, doi:10.1002/jgra.50092, 2013. 
Longcope, D. W. and Priest, E. R.: Fast magnetosonic waves launched by transient, current sheet reconnection, Physics of Plasmas, 14, 122905, doi:10.1063/1.2823023, 2007.

Luo, H., Kronberg, E. A., Grigorenko, E. E., Fränz, M., Daly, P. W., Chen, G. X., Du, A. M., Kistler, L. M., and Wei, Y.: Evidence of strong energetic ion acceleration in the near-Earth magnetotail, Geophys. Res. Lett., 41, 3724-3730, doi:10.1002/2014GL060252, 2014.

Lutsenko, V. N.: Almost Monoenergetic Ions: New Support for Alfven Ideas on the Role of Electric Currents in Space Plasmas?, Phys. Chem. Earth Pt. C, 26, 49-53, doi:10.1016/S14641917(00)00089-1, 2001.

Lutsenko, V. N. and Kudela, K.: Almost monoenergetic ions near the Earth's magnetosphere boundaries, Geophys. Res. Lett., 26, 413-416, doi:10.1029/1999GL900002, 1999.

Lutsenko, V. N., Kudela, K., and Sarris, E. T.: The DOK-2 Experiment to Study Energetic Particles by the Tail Probe and Auroral Probe Satellites in the INTERBALL Project, Cosmic Res., 36, 98-107, 1998.

Lutsenko, V. N., Gavrilova, E. A., and Grechko, T. V.: Statistics of fine dispersion structures events in energetic particle spectra: their origin and role in the outer magnetosphere, Ann. Geophys., 26, 2097-2110, doi:10.5194/angeo-26-2097-2008, 2008.

Lyons, L. R.: Electron energization in the geomagnetic tail current sheet, J. Geophys. Res., 89, 5479-5487, doi:10.1029/JA089iA07p05479, 1984.

Lyons, L. R. and Speiser, T. W.: Evidence for current sheet acceleration in the geomagnetic tail, J. Geophys. Res., 87, 2276-2286, doi:10.1029/JA087iA04p02276, 1982.

Meng, C.-I., Lui, A. T. Y., Krimigis, S. M., Ismail, S., and Williams, D. J.: Spatial distribution of energetic particles in the distant magnetotail, J. Geophys. Res., 86, 5682-5700, doi:10.1029/JA086iA07p05682, 1981.

Milovanov, A. V. and Zelenyi, L. M.: "Strange" Fermi processes and power-law nonthermal tails from a self-consistent fractional kinetic equation, Phys. Rev. E, 64, 052101, doi:10.1103/PhysRevE.64.052101, 2001.

Moebius, E., Scholer, M., Hovestadt, D., Paschmann, G., and Gloeckler, G.: Energetic particles in the vicinity of a possible neutral line in the plasma sheet, J. Geophys. Res., 88, 7742-7752, doi:10.1029/JA088iA10p07742, 1983.

Nakamura, R., Baumjohann, W., Mouikis, C., Kistler, L. M., Runov, A., Volwerk, M., Asano, Y., Vörös, Z., Zhang, T. L., Klecker, B., Rème, H., and Balogh, A.: Spatial scale of highspeed flows in the plasma sheet observed by Cluster, Geophys. Res. Lett., 31, L09804, doi:10.1029/2004GL019558, 2004.

Nakamura, R., Retinò, A., Baumjohann, W., Volwerk, M., Erkaev, N., Klecker, B., Lucek, E. A., Dandouras, I., André, M., and Khotyaintsev, Y.: Evolution of dipolarization in the nearEarth current sheet induced by Earthward rapid flux transport, Ann. Geophys., 27, 1743-1754, doi:10.5194/angeo-27-17432009, 2009.

Nakamura, R., Baumjohann, W., Panov, E., Volwerk, M., Birn, J., Artemyev, A., Petrukovich, A. A., Amm, O., Juusola, L., Kubyshkina, M. V., Apatenkov, S., Kronberg, E. A., Daly, P. W., Fillingim, M., Weygand, J. M., Fazakerley, A., and Khotyaintsev, Y.: Flow bouncing and electron injection observed by Cluster, J. Geophys. Res., 118, 2055-2072, doi:10.1002/jgra.50134, 2013.
Nakamura, T. K. M., Nakamura, R., Alexandrova, A., Kubota, Y., and Nagai, T.: Hall magnetohydrodynamic effects for threedimensional magnetic reconnection with finite width along the direction of the current, J. Geophys. Res., 117, A03220, doi:10.1029/2011JA017006, 2012.

Ohtani, S., Nosé, M., Christon, S. P., and Lui, A. T. Y.: Energetic $\mathrm{O}^{+}$and $\mathrm{H}^{+}$ions in the plasma sheet: Implications for the transport of ionospheric ions, J. Geophys. Res., 116, A10211, doi:10.1029/2011JA016532, 2011.

Ono, Y., Nosé, M., Christon, S. P., and Lui, A. T. Y.: The role of magnetic field fluctuations in nonadiabatic acceleration of ions during dipolarization, J. Geophys. Res., 114, 5209, doi:10.1029/2008JA013918, 2009.

Onofri, M., Isliker, H., and Vlahos, L.: Stochastic Acceleration in Turbulent Electric Fields Generated by 3D Reconnection, Phys. Rev. Lett., 96, 151102, doi:10.1103/PhysRevLett.96.151102, 2006.

Pavlos, G. P., Sarris, E. T., and Kalliabetsos, G.: Monitoring of energy spectra of particle bursts in the plasma sheet and magnetosheath, Plan. Sp. Sci., 33, 1109-1118, doi:10.1016/00320633(85)90069-8, 1985.

Perri, S., Greco, A., and Zimbardo, G.: Stochastic and direct acceleration mechanisms in the Earth's magnetotail, Geophys. Res. Lett., 36, L04103, doi:10.1029/2008GL036619, 2009.

Perri, S., Zimbardo, G., and Greco, A.: On the energization of protons interacting with 3-D time-dependent electromagnetic fields in the Earth's magnetotail, J. Geophys. Res., 116, A05221, doi:10.1029/2010JA016328, 2011.

Retinò, A., Nakamura, R., Vaivads, A., Khotyaintsev, Y., Hayakawa, T., Tanaka, K., Kasahara, S., Fujimoto, M., Shinohara, I., Eastwood, J. P., André, M., Baumjohann, W., Daly, P. W., Kronberg, E. A., and Cornilleau-Wehrlin, N.: Cluster observations of energetic electrons and electromagnetic fields within a reconnecting thin current sheet in the Earth's magnetotail, J. Geophys. Res., 113, A12215, doi:10.1029/2008JA013511, 2008.

Runov, A., Sergeev, V. A., Nakamura, R., Baumjohann, W., Apatenkov, S., Asano, Y., Takada, T., Volwerk, M., Vörös, Z., Zhang, T. L., Sauvaud, J.-A., Rème, H., and Balogh, A.: Local structure of the magnetotail current sheet: 2001 Cluster observations, Ann. Geophys., 24, 247-262, doi:10.5194/angeo-24-2472006, 2006.

Runov, A., Angelopoulos, V., Sitnov, M. I., Sergeev, V. A., Bonnell, J., McFadden, J. P., Larson, D., Glassmeier, K., and Auster, U.: THEMIS observations of an earthwardpropagating dipolarization front, Geophys. Res. Lett., 36, L14106, doi:10.1029/2009GL038980, 2009.

Runov, A., Angelopoulos, V., Zhou, X.-Z., Zhang, X.-J., Li, S., Plaschke, F., and Bonnell, J.: A THEMIS multicase study of dipolarization fronts in the magnetotail plasma sheet, J. Geophys. Res., 116, A05216, doi:10.1029/2010JA016316, 2011.

Runov, A., Angelopoulos, V., and Zhou, X.-Z.: Multipoint observations of dipolarization front formation by magnetotail reconnection, J. Geophys. Res., 117, A05230, doi:10.1029/2011JA017361, 2012.

Sarafopoulos, D. V.: A physical mechanism producing suprathermal populations and initiating substorms in the Earth's magnetotail, Ann. Geophys., 26, 1617-1639, doi:10.5194/angeo-261617-2008, 2008. 
Sarafopoulos, D. V., Sidiropoulos, N. F., Sarris, E. T., Lutsenko, V., and Kudela, K.: The dawn-dusk plasma sheet asymmetry of energetic particles: An interball perspective, J. Geophys. Res., 106, 13053-13066, doi:10.1029/2000JA900157, 2001.

Sarris, E. T., Krimigis, S. M., and Armstrong, T. P.: Observations of magnetospheric bursts of high-energy protons and electrons at approximately 35 earth radii with Imp 7, J. Geophys. Res., 81, 2341-2355, doi:10.1029/JA081i013p02341, 1976.

Sarris, E. T., Krimigis, S. M., Lui, A. T. Y., Ackerson, K. L., Frank, L. A., and Williams, D. J.: Relationship between energetic particles and plasmas in the distant plasma sheet, Geophys. Res. Lett., 8, 349-352, doi:10.1029/GL008i004p00349, 1981.

Sauvaud, J.-A., Koperski, P., Beutier, T., Barthe, H., Aoustin, C., Thocaven, J. J., Rouzaud, J., Penou, E., Vaisberg, O., and Borodkova, N.: The INTERBALL-Tail ELECTRON experiment: initial results on the low-latitude boundary layer of the dawn magnetosphere, Ann. Geophys., 15, 587-595, doi:10.1007/s00585-9970587-z, 1997.

Scholer, M., Hovestadt, D., Klecker, B., Gloeckler, G., Ipavich, F. M., and Fan, C. Y.: Anisotropies and flows of suprathermal particles in the distant magnetotail ISEE 3 observations, Geophys. Res. Lett., 10, 1203-1206, doi:10.1029/GL010i012p01203, 1983.

Scholer, M., Sckopke, N., Hovestadt, D., and Ipavich, F. M.: Relation between energetic electrons, protons, and the thermal plasma sheet population - Plasma sheet recovery events, J. Geophys. Res., 90, 2735-2743, doi:10.1029/JA090iA03p02735, 1985.

Sharma, A. S., Nakamura, R., Runov, A., Grigorenko, E. E., Hasegawa, H., Hoshino, M., Louarn, P., Owen, C. J., Petrukovich, A., Sauvaud, J.-A., Semenov, V. S., Sergeev, V. A., Slavin, J. A., Sonnerup, B. U. Ö., Zelenyi, L. M., Fruit, G., Haaland, S., Malova, H., and Snekvik, K.: Transient and localized processes in the magnetotail: a review, Ann. Geophys., 26, 9551006, doi:10.5194/angeo-26-955-2008, 2008.

Sitnov, M. I., Swisdak, M., and Divin, A. V.: Dipolarization fronts as a signature of transient reconnection in the magnetotail, J. Geophys. Res., 114, A04202, doi:10.1029/2008JA013980, 2009.

Sitnov, M. I., Buzulukova, N., Swisdak, M., Merkin, V. G., and Moore, T. E.: Spontaneous formation of dipolarization fronts and reconnection onset in the magnetotail, Geophys. Res. Lett., 40, 22-27, doi:10.1029/2012GL054701, 2013.

Speiser, T. W.: Particle Trajectories in Model Current Sheets, 1, Analytical Solutions, J. Geophys. Res., 70, 4219-4226, doi:10.1029/JZ070i017p04219, 1965.

Speiser, T. W.: Particle Trajectories in Model Current Sheets, 2, Applications to Auroras Using a Geomagnetic Tail Model, J. Geophys. Res., 72, 3919-3932, doi:10.1029/JZ072i015p03919, 1967.

Taktakishvili, A. L., Zelenyi, L. M., Lutsenko, V. N., and Kudela, K.: On the Spectra of Energetic Particles in the Earth's Magnetotail, Cosmic Res., 36, 265-273, 1998.

Ukhorskiy, A. Y., Sitnov, M. I., Merkin, V. G., and Artemyev, A. V.: Rapid acceleration of protons upstream of earthward propagating dipolarization fronts, J. Geophys. Res., 118, 4952-4962, doi:10.1002/jgra.50452, 2013.

Wang, C., Lyons, L. R., Wolf, R. A., Nagai, T., Weygand, J. M., and Lui, A. T. Y.: Plasma sheet $\mathrm{PV}^{5 / 3}$ and $\mathrm{nV}$ and associated plasma and energy transport for different convec- tion strengths and AE levels, J. Geophys. Res., 114, A00D02, doi:10.1029/2008JA013849, 2009.

Wang, L., Lin, R. P., Larson, D. E., and Luhmann, J. G.: Domination of heliosheath pressure by shock-accelerated pickup ions from observations of neutral atoms, Nature, 454, 81-83, doi:10.1038/nature07068, 2008.

Wilken, B., Daly, P. W., Mall, U., Aarsnes, K., Baker, D. N., Belian, R. D., Blake, J. B., Borg, H., Büchner, J., Carter, M., Fennell, J. F., Friedel, R., Fritz, T. A., Gliem, F., Grande, M., Kecskemety, K., Kettmann, G., Korth, A., Livi, S., McKenna-Lawlor, S., Mursula, K., Nikutowski, B., Perry, C. H., Pu, Z. Y., Roeder, J., Reeves, G. D., Sarris, E. T., Sandahl, I., Søraas, F., Woch, J., and Zong, Q.-G.: First results from the RAPID imaging energetic particle spectrometer on board Cluster, Ann. Geophys., 19, 1355-1366, doi:10.5194/angeo-19-1355-2001, 2001.

Williams, D. J., McEntire, R. W., Schlemm, C., Lui, A. T. Y., Gloeckler, G., Christon, S. P., and Gliem, F.: Geotail Energetic Particles and Ion Composition Instrument, J. Geomag. Geoelect., 46, 39-57, 1994.

Wygant, J. R., Cattell, C. A., Lysak, R., Song, Y., Dombeck, J., McFadden, J., Mozer, F. S., Carlson, C. W., Parks, G., Lucek, E. A., Balogh, A., Andre, M., Reme, H., Hesse, M., and Mouikis, C.: Cluster observations of an intense normal component of the electric field at a thin reconnecting current sheet in the tail and its role in the shock-like acceleration of the ion fluid into the separatrix region, J. Geophys. Res., 110, A09206, doi:10.1029/2004JA010708, 2005.

Yermolaev, Yu. I., Fedorov, A. O., Vaisberg, O. L., Balebanov, V. M., Obod, Yu. A., Jimenez, R., Fleites, J., Llera, L., and Omelchenko, A. N.: Ion distribution dynamics near the Earth's bow shock: first measurements with the $2 \mathrm{D}$ ion energy spectrometer CORALL on the INTERBALL/Tail-probe satellite, Ann. Geophys., 15, 533-541, doi:10.1007/s00585-997-0533-0, 1997.

Zelenyi, L., Artemyev, A., and Petrukovich, A.: Properties of magnetic field fluctuations in the Earth's magnetotail and implications for the general problem of structure formation in hot plasmas, Space Sci. Rev., online first, doi:10.1007/s11214-014-00377, 2014.

Zelenyi, L. M. and Milovanov, A. V.: Fractal topology and strange kinetics: from percolation theory to problems in cosmic electrodynamics, Physics Uspekhi, 47, 749-788, doi:10.1070/PU2004v047n08ABEH001705, 2004.

Zelenyi, L. M., Lominadze, J. G., and Taktakishvili, A. L.: Generation of the energetic proton and electron bursts in planetary magnetotails, J. Geophys. Res., 95, 3883-3891, doi:10.1029/JA095iA04p03883, 1990a.

Zelenyi, L. M., Zogin, D. V., and Büchner, J.: Quasiadiabatic dynamics of charged particles in the tail of the magnetosphere, Cosmic Res., 28, 369-380, 1990b.

Zelenyi, L. M., Dolgonosov, M. S., Grigorenko, E. E., and Sauvaud, J.: Universal properties of the nonadiabatic acceleration of ions in current sheets, Soviet Journal of Experimental and Theoretical Physics Letters, 85, 187-193, doi:10.1134/S0021364007040017, 2007.

Zelenyi, L. M., Artemyev, A., Malova, H., Milovanov, A. V., and Zimbardo, G.: Particle transport and acceleration in a timevarying electromagnetic field with a multi-scale structure, Phys. Lett. A, 372, 6284-6287, doi:10.1016/j.physleta.2008.08.035, 2008. 
Zelenyi, L. M., Rybalko, S. D., Artemyev, A. V., Petrukovich, A. A., and Zimbardo, G.: Charged particle acceleration by intermittent electromagnetic turbulence, Geophys. Res. Lett., 381, L17110, doi:10.1029/2011GL048983, 2011.

Zelenyi, L. M., Neishtadt, A. I., Artemyev, A. V., Vainchtein, D. L., and Malova, H. V.: Quasiadiabatic dynamics of charged particles in a space plasma, Physics Uspekhi, 56, 347, doi:10.3367/UFNe.0183.201304b.0365, 2013.

Zhou, X., Angelopoulos, V., Sergeev, V. A., and Runov, A.: Accelerated ions ahead of earthward propagating dipolarization fronts, J. Geophys. Res., 115, A00I03, doi:10.1029/2010JA015481, 2010.
Zieger, B., Retinò, A., Nakamura, R., Baumjohann, W., Vaivads, A., and Khotyaintsev, Y.: Jet front-driven mirror modes and shocklets in the near-Earth flow-braking region, Geophys. Res. Lett., 38, L22103, doi:10.1029/2011GL049746, 2011.

Zimbardo, G.: Heavy ion reflection and heating by collisionless shocks in polar solar corona, Planet. Space Sci., 59, 468-474, doi:10.1016/j.pss.2010.03.010, 2011.

Zimbardo, G., Greco, A., Sorriso-Valvo, L., Perri, S., Vörös, Z., Aburjania, G., Chargazia, K., and Alexandrova, O.: Magnetic Turbulence in the Geospace Environment, Space Sci. Rev., 156, 89-134, doi:10.1007/s11214-010-9692-5, 2010. 